\title{
Prelude and sarabande
}

\author{
J D Warren
}

J R Soc Med 2005;98:213-214

Dear reader in 2055: Susan was my Christmas leukaemia, and anniversaries always put me in mind of her. The phenomenon is well recognized by junior staff covering haematology units during the festive season-the patient with acute leukaemia who presents just in time to ensure that Christmas Day will vanish in a frantic round of bloods, biopsies, difficult conversations, futile phone calls to understaffed laboratories, heroic attempts to source obscure antibiotics, hourly consultant rounds, and more bloods. Even as I began my standard speech about the need for tests and the evils of jumping to conclusions I knew I was fooling no-one; Susan was a cytogenetics technician and plainly terrified.

I cannot imagine what haematology wards will be like in your time; in ours, they are places where fresh flowers are banned and gaiety is generally in short supply. On Christmas Eve the marrow biopsy; on Christmas Day the diagnosis; and on Boxing Day, the numbers began; platelets, white cells, probabilities of cure. There will be different numbers (so we like to think) by the time you read this. Susan listened in silence, clutching her fiancé's hand, as the consultant ran through her numbers for the umpteenth time. Later that evening I sat on the edge of her bed, as talk turned to lumbar punctures. 'Will it hurt?' she asked. She was of an age with me. I knew the usual condescensions wouldn't wash. Brushing the dust of imaginary blooms from her Central Linen Service blanket, I told her I would do my best.

Besides the lumbar punctures, there were more pervasive miseries - aphthous stomatitis, neutropenic fever, diarrhoea, the death of friends, alopecia, the rotation of ward staff, the dwindling of veins. As we chanted numbers round her bed in our morning litany, Susan's eyes grew daily larger and more luminous, the skin withering from her bones in the cytotoxic firestorm we had unleashed. Slowly and inevitably, I learned other things about her besides her platelet count. On her bedside table I saw Love in the Time of Cholera and was prompted to read it for the first time, its scent of bitter almonds and its florid gestures blending quietly with vomit, dimethylsulphoxide (sweetly sick and

Jason Warren, FRACP, is an honorary consultant neurologist at the Institute of Neurology, London.

Dementia Research Unit, Institute of Neurology, Queen Square,

London WC1N 3BG, UK

E-mail: warren@dementia.ion.ucl.ac.uk unmistakable, it still takes me straight back) and the quixotic weirdness of the ward's little world. Among other things, the book is a love song to the Bach cello suites, which remain my good friends. One day, over yet another spinal needle, Susan and I discovered we had both recently acquired convertibles. Earnestly and with chagrin, we exchanged comments over the lack of luggage space - both, I suppose, thinking of long summer evenings and crisp autumn days. Another time she appropriated the ward's CD player and its tiny library of tinny disks: thereafter Ashkenazy often kept us company, a surreal conjunction of crystal-clear arpeggios and crystal-clear CSF. I like to think I would still be able to find that disk in 2055 .

Midway through Susan's treatment, the numbers changed again. What began as a low grade temperature with borderline oxygen saturations on room air had become a devastating pneumonia by the small hours. My patient sat hunched forward, gasping over the hiss of nasal specs. The CD player yawned open, its silver disk motionless, beside the wreck of her bedclothes. I stared at the portable chest film with its sinister white smudges and called the crash team. One by one, relatives and consultants were woken. The intensive therapy unit registrar murmured numbers down the phone, the same quiet mantra I had heard before on a dozen pre-dawn rendezvous - available beds, ventilation indices, cell counts, odds of survival, days of support. As Susan was intubated in advance of her brief but significant trolley ride, I was thinking of appalling long shots - the single manuscript by which we know Catullus, the single cell division by which we have all the lives that have been. What threads, I wonder, will bind us to youhalf a century hence?

I looked after Susan into her hard-won first remission. The day she left the ward she gave me a card. Above her name she had written, 'Thanks for making my lumbar punctures bearable'. For a long while I kept it in the ward office, even after I left the war zone of haematology for the more genteel no-man's land of my chosen specialty. There it continued to haunt me, with that strange permanence of words denied to the world of men.

Why am I telling you all this, a lifetime separate from me, in a world that will no longer be my world? Partly in hope; partly in curiosity; partly in sympathy.

I hope (though I cannot wholly believe it) that our medicine will seem quaint and barbarous to you, that you 
will forgive us our flowerless places, our treatments that are (almost) worse than the diseases they sometimes cure, the long list of ills we cannot treat at all.

I hope that graft-versus-host disease, AIDS and malaria belong to your past. I hope that your multiresistant superbugs are all of the silicon variety. I hope that you have new sets of numbers to mumble, over different diseases (on those acute neurology wards where patients with Christmas dementia fill the cancer beds of a bygone age).

I am curious to know (though I cannot help but believe it) whether your hearts will still cry out for Chopin and Bach (or if by then it will be Birtwistle and Glass). I wonder what patients will keep by their bedsides (books, I would guess, will be found too useful to dispense with entirely, for all their intense fragility). I wonder how missives of thanks will be treasured, once the piles of dog-eared case-notes that once propped them up are consigned to the paperless limbo of a better organized age. I wonder whether lumbar puncture will itself be a lost art, like pneumoencephalography, spun urines, auscultation, and the writing of letters.

But when I try to imagine myself into your world, it is mostly sympathy that I feel-sympathy for our common predicament. I cannot say what the doctors of your time will have to cram in medical school, how they will be apprenticed to their art, where they will work, or how they will be validated (and revalidated), but one thing is certain. Some time each of them will have to learn how to tell their patient it will hurt. This was true on the windy plain of
Troy and the sunny beaches of Cos and, before that, on the banks of the Nile; it is true for us, and it will be true for you, too. Our god is two-faced Janus as much as Asclepius, occupying as he does the precarious crossroads where the fierce beauty of the heart meets the calamity of experience. Had we more art, we would admit this to ourselves; fortunately, others have said it on our behalf before and better. It is presumably the reason why Blake wrote his poem about the tiger; and why Carpaccio painted an eternal face-off between the dragon, with his impressive pile of body parts, and St Jerome with his small white dog and cosy book-lined study, on opposite walls of the Giorgio degli Schiavoni.

We do not have the luxury to throw down our spears (or for that matter, take up our paintbrushes). Our god will always live in the shadow of his elder brothers Thanatos, the more capable, and Morpheus, the more beloved. You may no longer have Venice (or tigers), but your predicament will be the same as ours. It is of course a corollary of the real doctors' dilemma - the undiscovered reason why some lives are too short, and some too long, and some simply unfinished. I hope you really do still have that disk of Ashkenazy playing Chopin, so clearly does the music say that time is not the arbiter in such things (handy for anniversaries). The A major prelude, at just sixteen bars, is long enough to contain an entire world. It will not stop you from becoming grumpy with patients or wishing them away on occasion, but it may remind you that they are all irreplaceable.

Prelude Opus 28 No. 7

by Frimincic curin
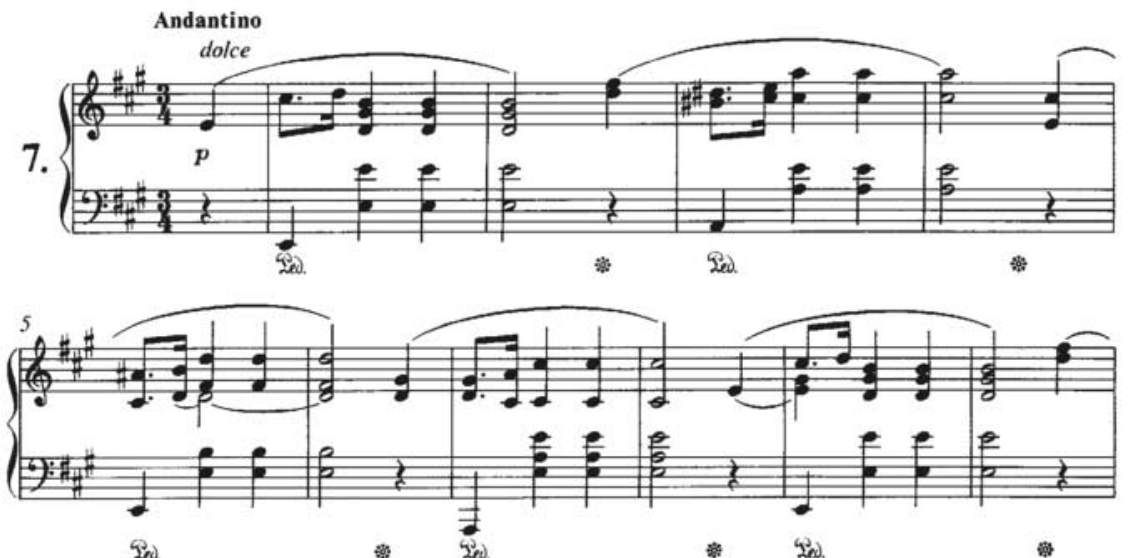

Sod.

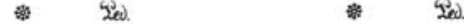

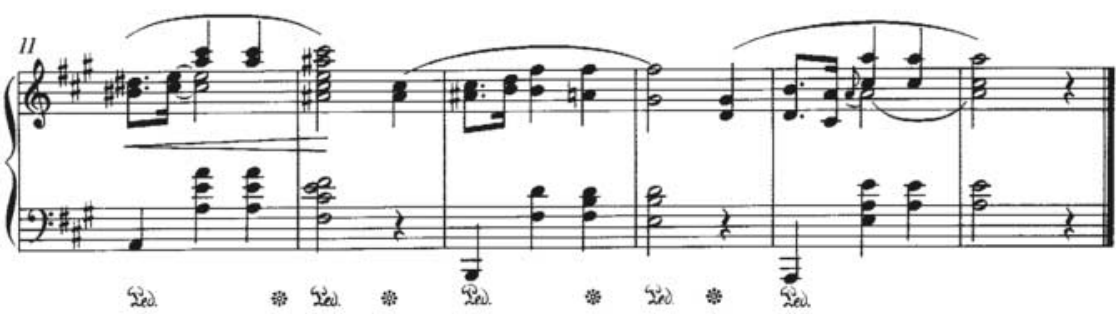

Led

20. 